\title{
GASC1 promotes glioma progression by enhancing NOTCH1 signaling
}

\author{
ZHENGZHENG XIAO $^{1}$, XIAOLI YANG ${ }^{2}$, ZEBIN LIU $^{1}$, ZHENG SHAO $^{1}$, CHAOJUN SONG $^{1}$, \\ $\mathrm{KUN}_{\mathrm{ZHANG}}{ }^{3}$, XIAOBIN WANG ${ }^{4}$ and ZHENGWEI LI ${ }^{5}$
}

\author{
${ }^{1}$ Department of Neurosurgery, Henan Key Laboratory of Cancer Epigenetics, Cancer Institute, ${ }^{2}$ Department of General Practice, \\ The First Affiliated Hospital and College of Clinical Medicine of Henan University of Science and Technology, \\ Luoyang, Henan 471003; ${ }^{3}$ Spine Tumor Center, Department of Orthopedic Oncology, Changzheng Hospital, \\ Second Military Medical University, Shanghai 210011; ${ }^{4}$ Department of Urology, Carson International Cancer Centre, \\ Shenzhen University General Hospital and Shenzhen University Clinical Medical Academy Centre, \\ Shenzhen University, Shenzhen, Guangdong 518000; ${ }^{5}$ Department of Neurosurgery, \\ Zhongnan Hospital of Wuhan University, Wuhan, Hubei 430071, P.R. China
}

Received July 2, 2020; Accepted January 21, 2021

DOI: $10.3892 / \mathrm{mmr} .2021 .11949$

\begin{abstract}
Recent studies have reported that gene amplified in squamous cell carcinoma 1 (GASC1) is involved in the progression of several types of cancer. However, whether GASC1 promotes glioma progression remains unknown. Therefore, the present study aimed to investigate the effect of GASC1 exposure on glioma tumorigenesis. The western blot demonstrated that grade III and IV glioma tissues exhibited a higher mRNA and protein expression of GASC1. Moreover, $\mathrm{CD}_{133}{ }^{+} \mathrm{U} 87$ or U251 cells from magnetic cell separation exhibited a higher GASC1 expression. Invasion Transwell assay, clonogenic assay and wound healing assay have shown that GASC1 inhibition using a pharmacological inhibitor and specific short hairpin (sh)RNA suppressed the invasive, migratory and tumorsphere forming abilities of primary culture human glioma cells. Furthermore, GASC1-knockdown decreased notch receptor (Notch) responsive protein hes family bHLH transcription factor 1 (Hes1) signaling. GASC1 inhibition reduced notch receptor 1 (NOTCH1) expression, and a NOTCH1 inhibitor enhanced the effects of GASC1 inhi-
\end{abstract}

Correspondence to: Dr Zhengzheng Xiao, Department of Neurosurgery, Henan Key Laboratory of Cancer Epigenetics, Cancer Institute, The First Affiliated Hospital and College of Clinical Medicine of Henan University of Science and Technology, Surgical Building, 24 Jinghua Road, Luoyang, Henan 471003, P.R. China E-mail: xiaozhengly@163.com

Dr Zhengwei Li, Department of Neurosurgery, Zhongnan Hospital of Wuhan University, 169 East Lake Road, Wuhan, Hubei 430071, P.R. China

E-mail: lizhengwei1006@163.com

Key words: gene amplified in squamous cell carcinoma 1, notch receptor 1 , stemness, glioma bition on the $\mathrm{CD} 133^{+} \mathrm{U} 87$ or $\mathrm{U} 251$ cell tumorsphere forming ability, while NOTCH1 overexpression abrogated these effects. In addition, the GASC1 inhibitor caffeic acid and/or the NOTCH1 inhibitor DAPT (a $\gamma$-Secretase Inhibitor), efficiently suppressed the human glioma xenograft tumors. Thus, the present results demonstrated the importance of GASC1 in the progression of glioma and identified that GASC1 promotes glioma progression, at least in part, by enhancing $\mathrm{NOTCH}$ signaling, suggesting that GASC1/NOTCH1 signaling may be a potential therapeutic target for glioma treatment.

\section{Introduction}

Glioma is the most common type of primary malignant brain tumor and the leading cause of intrinsic brain tumor-related mortality worldwide $(1,2)$. The annual incidence rate of glioma is 6 new cases per 100,000 individuals per year in China $(2,3)$. Glioblastoma is the most malignant pathological type of glioma. The recommended standard therapy for glioblastoma includes maximal surgical resection followed by concurrent radiation therapy with temozolomide and subsequent adjuvant temozolomide therapy (2). Although a markedly higher survival time along with an acceptable quality of life was achieved in patients with gliomas, their treatment remains challenging. The median survival time of patients with glioblastoma is estimated to be only 15 months, with the 5-year survival rate of patients at $5 \%(2,4)$. These epidemiologic results reflect the low efficiency of current treatments, suggesting the urgent requirement for new therapeutic strategies.

Gene amplified in squamous cell carcinoma 1 (GASC1), also known as Lysine Demethylase 4C (KDM4C) and Jumonji C domain-containing oxygenase D2C (JMJD2C), is a gene on chromosome 9p24.1 that encodes lysine-specific demethylase $4 \mathrm{C}$, which demethylates histone $\mathrm{H} 3$ and generates formaldehyde and succinate (5). GASC1 can regulate the expression of important cancer genes via the demethylation of tri- or di-methylation of histone $\mathrm{H} 3$ at lysine 9 (H3K9me3/me2) 
at corresponding promoter regions (6). Previous studies have revealed that GASC1 is widely expressed and serves as a transforming oncogene in several types of cancer, including lymphoma, medulloblastoma, lung, prostate and breast cancer (7-14). Moreover, GASC1 was found to be highly expressed in the brain astrocytes, and the brain of GASC1-hypomorphic mutant mice displayed an increased number of astrocytes (12), suggesting a possible role of GASC1 in the development of glioma. However, to date, the link between the GASC1 expression and the progression of glioma remains unknown.

Due to the capabilities of self-renewal, differentiation and tumorigenicity, glioma stem cells (GSCs) have been suggested to be key contributors to glioma tumorigenesis, treatment resistance and tumor recurrence $(15,16)$. Due to the promising results of treatment using molecular targets, there has been increasing interest in therapeutic strategies using small-molecule targeted drugs against cancer stem cells. Our previous studies revealed that GASC1 promotes stemness of esophageal squamous cell carcinoma, and that nuclear-enriched abundant transcript 1 silencing suppresses glioma stem-like properties $(14,17)$. In the present study, the GASC1 expression was examined in World Health Organization (WHO) grade II, III and IV glioma tissues. The proliferation, invasion, migration and stemness of glioma cells in vitro and in vivo under GASC1 inhibition exposure were also determined in invasion Transwell, clonogenic and wound healing assays.

\section{Materials and methods}

Reagent and antibodies. GASC1 (cat. no. ab85454), notch receptor 1 (NOTCH1) (cat. no. ab8925), GLI family zinc finger 1 (Gli1; cat. no. ab49314), hes family bHLH transcription factor 1 (Hes1; cat. no. ab71559), Bax (cat. no. ab32503), S100 (cat. no. ab52642), $\beta$-catenin (cat. no. ab16051), CD133 (cat. no. ab16518), nestin (cat. no. ab105389) and Ki67 (sp6; cat. no. ab16667) antibodies were obtained from Abcam. Cyclin D1 (cat. no. sc-8396) and $\beta$-actin (cat. no. sc-81178) primary antibodies were purchased from Santa Cruz Biotechnology, Inc.

Glioma specimens. The study protocol was approved by the Research Ethics Committee of The First Affiliated Hospital of Henan University of Science and Technology Institutional Review Board (approval no. 2013-08). Written informed consent was obtained from all patients. Gliomas were diagnosed with preoperative magnetic resonance imaging and postoperative histopathology, based on the WHO guidelines for the diagnosis and treatment of glioma (18). All patients ( 9 males, 9 females; age range 28-71 years; mean age, 51 years; interquartile range, 40-62 years) received surgery between July 2013 and July 2019 at the Department of Neurosurgery, The First Affiliated Hospital of Henan University of Science and Technology. Each tissue sample was bisected. One half was frozen for protein and RNA extraction, and the other half were fixed with 10\% neutral buffered formalin (cat. no. DF0111; Beijing Leagene Biotechnology Co., Ltd.) overnight at room temperature (RT) followed by an embedding in paraffin wax.

Cell lines and culture protocols. The U87 human glioblastoma of unknown origin (cat. no. Tchu 138) and U251 human glio- blastoma cell line (cat. no. Tchu 58) were purchased from the Cell Bank of Chinese Academy of Sciences. In this study, the U87 cell line was authenticated using STR profiling (data not shown). As described in our previous study (17), cells were maintained in DMEM (cat. no. DZPYG0051; Wuhan Boster Biotechnology Co., Ltd.) containing 10\% FBS (Gibco; Thermo Fisher Scientific, Inc.), $100 \mathrm{U} / \mathrm{ml}$ penicillin and $50 \mu \mathrm{g} / \mathrm{ml}$ streptomycin at $37^{\circ} \mathrm{C}$ in a humidified $\mathrm{CO}_{2}$ incubator $\left(5 \% \mathrm{CO}_{2}\right.$, 95\% air).

For glioma primary cultured cells, the Human Tumor Dissociation kit (cat. no. 130-095-929; Miltenyi Biotec $\mathrm{GmbH}$ ) was used with the gentleMACS ${ }^{\mathrm{TM}}$ Dissociator (cat. no. DXT-130-096-730; Miltenyi Biotec $\mathrm{GmbH}$ ) to enzymatically digest the tissues, and human Anti-Fibroblast MicroBeads (cat. no. 130-050-601; Miltenyi Biotec $\mathrm{GmbH}$ ) were used to filter the tissue lysates. For each experiment, tissues from one patient were used. In order to obtain enough prolactinoma tissues for primary culture, only huge and invasive prolactinoma tissues were selected. Following surgery, tumor specimens were placed in complete DMEM on ice and transferred to the lab. Fresh resected brain glioma tissues were washed in PBS at $37^{\circ} \mathrm{C}$. Then, $1 \mathrm{ml}$ Human Tumor Dissociation reagent (cat. no. 130-095-929; Miltenyi Biotec, Inc.) was added, the tissues were placed into a $37^{\circ} \mathrm{C} \mathrm{CO}_{2}$ incubator for $60 \mathrm{~min}$, and the suspension was pipetted every $10 \mathrm{~min}$. To obtain adenoma cell preparations deprived from rapidly dividing fibroblasts, dispersed cells were filtered through a magnetic bead column coated with human Anti-Fibroblast MicroBeads (cat. no. 130-050-601; Miltenyi Biotec $\mathrm{GmbH}$ ), according to the manufacturer's instructions. The tissue-digested solution was filtered using a $40-\mu \mathrm{m}$ steel mesh. The cell suspensions were cultured in DMEM containing 10\% FBS and $100 \mathrm{U} / 100 \mu \mathrm{g} / \mathrm{ml}$ penicillin-streptomycin in a humidified incubator at $37^{\circ} \mathrm{C}$ with $5 \% \mathrm{CO}_{2}$.

CD133 ${ }^{+}$cell isolation. As described in our previous study (17), U87 cells, U251 cells or human glioma primary culture cells were isolated using CD133 magnetic microbeads. The cell suspensions were collected, washed with PBS and incubated with magnetic microbeads conjugated with the anti-CD133 antibody at $20 \mu \mathrm{g} / \mathrm{ml}$ and $4^{\circ} \mathrm{C}$ for $30 \mathrm{~min}$. CD133 $3^{+}$cells were isolated using CD133 (cat. no. 130097049; Miltenyi Biotec $\mathrm{GmbH}$ ). The QuadroMACS ${ }^{\mathrm{TM}}$ Separation Unit (Miltenyi Biotec $\mathrm{GmbH}$ ) was used for isolation. Prior to purification, the MACS $^{\circledR}$ (25 LD columns; Miltenyi Biotec $\mathrm{GmbH}$ ) columns were filled with warmed $\left(37^{\circ} \mathrm{C}\right) \mathrm{RPMI}$ (cat. no. PYG0006; Wuhan Boster Biotechnology Co.,Ltd.) or PBS. When the purification was conducted in order to synchronize the culture, the experimentation was performed under sterile conditions. The cells were digested and scattered, cells were then deposited on the top of the column (typically, $1 \mathrm{ml}$ at $25-50 \%$ hematocrit), which was held in a Quadro MACS ${ }^{\circledast}$ magnetic support (cat. no. 130-091-051; Miltenyi Biotec $\mathrm{GmbH}$ ). The column was removed from the magnetic support, a further $4 \mathrm{ml}$ culture medium was added and the eluent was recovered. This eluent was then centrifuged $\left(800 \times \mathrm{g}, 4^{\circ} \mathrm{C}\right.$ for $\left.3 \mathrm{~min}\right)$ and the supernatant was discarded. The pellet was resuspended and cultured. The purity of the isolated cells was confirmed via flow cytometric analysis using a Guava ${ }^{\circledR}$ easyCyte ${ }^{\mathrm{TM}} 8$ flow cytometer (EMD Millipore) with ModFit software 5.0 (Verity Software 
House). The isolated CD133+ cells were then cultured in DMEM-Nutrient F-12 (F12) supplemented with $20 \mathrm{ng} / \mu 1 \mathrm{hEGF,}$ $20 \mathrm{ng} / \mu \mathrm{l} \mathrm{bFGF}$ (both from Gibco; Thermo Fisher Scientific, Inc.), $1 \mathrm{x}$ B27 and $100 \mathrm{U} / 100 \mu \mathrm{g} / \mathrm{ml}$ penicillin-streptomycin in a humidified incubator at $37^{\circ} \mathrm{C}$ with $5 \% \mathrm{CO}_{2}$.

Cell transfection. pPLK/GFP+Puro-GASC1 short hairpin (sh)RNA (cat. no. 23081), pPLK/GFP+Puro non-targeting control vector, pIRES2-EGFP-NOTCH1 system (cat. no. PPL00782-2a) and pIRES2-EGFP lentiviral interference control vector (cat. no. 6029-1) were obtained from Geneppl Biotechnology Co., Ltd. A total of $2 \times 10^{5}$ glioma primary culture cells in DMEM were seeded into 6-well plates and cultured till they reached $\sim 70 \%$ confluence. The cells were then transfected with $100 \mathrm{nM}$ control or sample shRNA using the Lipofectamine ${ }^{\circledR} 3000$ (cat. no. L3000001; Thermo Fisher Scientific, Inc.) transfection reagent, following the manufacturer's instructions. Briefly, $25 \mu \mathrm{l}$ Opti-MEM $^{\text {Tм I }}$ medium (cat. no. L3000001; Thermo Fisher Scientific, Inc.) and $1.5 \mu \mathrm{l}$ Lipofectamine 3000 reagent were mixed in tube 1 . Next, $25 \mu \mathrm{l}$ Opti-MEM I medium, $250 \mathrm{ng}$ DNA $(2.5 \mu \mathrm{g} / \mu \mathrm{l})$ and $0.5 \mu 1 \mathrm{P} 3000^{\mathrm{TM}}$ reagent were mixed in tube 2 . Then, tube 2 solution was added to tube 1 and mixed well. The mixture was incubated at room temperature for $15 \mathrm{~min}$ and $50 \mu \mathrm{l}$ complex (tube 1 and 2) was added to cells. The plate was gently swirled to ensure homogeneous distribution of complex to the entire well. After $12 \mathrm{~h}$, the medium was replaced with fresh medium. The next day, the cells were selected using puromycin $(2 \mathrm{mg} / \mathrm{ml})$ for at least 3-4 days. A total of $48 \mathrm{~h}$ after transfection, cells were evaluated for further experiments.

Cell proliferation assay. A Cell Counting Kit-8 (CCK-8) kit (Roche Diagnostics) was used for the cell viability assay according to the manufacturer's instructions. Cells $\left(1 \times 10^{3}\right.$ cells/well) were transiently transfected and seeded in 96-well plates overnight at $37^{\circ} \mathrm{C}$, and then treated with stimulants for 3 days. CCK-8 (10 $\mu 1)$ was then added and the cells were incubated at $37^{\circ} \mathrm{C}$ for a further $4 \mathrm{~h}$. Colorimetric absorbance was measured at $450 \mathrm{~nm}$ using an ELISA microplate reader, with six replicates per experimental sample.

Tumorsphere formation assay. GSC growth medium was prepared by combining DMEM/F12 medium with B27 supplement (final concentration, 1x), EGF (final concentration, $20 \mathrm{ng} / \mathrm{ml}$ ), bFGF (final concentration, $10 \mathrm{ng} / \mathrm{ml}$ ) and penicillin/streptomycin (final concentration, $1 \mathrm{x}$ ). Tumorsphere formation assays were performed on $\mathrm{CD}_{133^{+}}$cells in 96-well plates in growth medium. A cell count was performed using Trypan Blue staining (room temperature for $4 \mathrm{~min}$ ) and a hemocytometer. Single tumorsphere cells were seeded at a density of 50 cells $/ \mathrm{ml}$ in $100 \mu \mathrm{l}$ GSC growth medium in a 96-well dish. The cells were incubated at $37^{\circ} \mathrm{C}, 5 \% \mathrm{CO}_{2}$ for 1 week to generate clonal neurospheres. The tumorspheres were then dissociated into single cells. Single cells from tumorspheres were seeded at a density of 20,000 cells $/ \mathrm{ml}$ in a $10 \mathrm{ml}$ GSC growth medium in a $10-\mathrm{cm}$ culture dish. The cells were incubated at $37^{\circ} \mathrm{C}, 5 \% \mathrm{CO}_{2}$ for 5 days to generate bulk cultured tumorspheres. The number of tumorspheres formed in each well was counted using a light Nikon ECLIPSE E100 microscope at a magnification of $\mathrm{x} 40$ or $\mathrm{x} 100$.
Cell cycle and apoptosis analysis. A total of $1 \times 10^{4}$ cells/plate were transiently transfected for $24 \mathrm{~h}$. The cells were then collected and fixed in $70 \%$ ethanol overnight at $-20^{\circ} \mathrm{C}$. Following washing, the fixed cells were incubated in PBS with FxCycle ${ }^{\mathrm{TM}}$ PI/RNase Staining Solution (cat. no. F10797; Invitrogen; Thermo Fisher Scientific, Inc.) with RNase A $(0.5 \mathrm{mg} / \mathrm{ml})$ and propidium iodide (PI; $50 \mu \mathrm{g} / \mathrm{ml})$ for $30 \mathrm{~min}$ at $37^{\circ} \mathrm{C}$. The percentage of cells in each phase of the cell cycle or apoptosis was quantified using a Guava ${ }^{\circledR}$ easyCyte 8 flow cytometer (EMD Millipore) with ModFit software 5.0 (Verity Software House). Blue sub-G1 accumulation represented apoptotic cells containing only fractional DNA content. The cells in each group were quantified based on three independent experiments.

Western blot analysis. Western blotting was routinely performed. Protein extraction from cells was performed using RIPA Lysis and Extraction Buffer (cat. no. 89901; Thermo Fisher Scientific, Inc.) following the manufacturer's protocol. Briefly, cells were washed using cold PBS for twice. Then 1 per $75-\mathrm{cm}^{2}$ flask containing cells were added with $1 \mathrm{ml}$ Cold RIPA Buffer on ice for $5 \mathrm{~min}$ and the plate was swirled occasionally for uniform spreading. The lysate was collected and transferred to a microcentrifuge tube. The tube was centrifuged at $\sim 14,000 \mathrm{x}$ g for $15 \mathrm{~min}$ to collect the cell debris.

Protein determination was performed using the Pierce ${ }^{\mathrm{TM}}$ Rapid Gold BCA Protein Assay kit (cat. no. A53225; Thermo Fisher Scientific, Inc.). First, $20 \mu 1$ of each standard sample replicate was pipetted into a microplate well, while $200 \mu \mathrm{l}$ of the wash buffer was added to each well. The plate was thoroughly mixed on a plate shaker for $30 \mathrm{sec}$ and subsequently incubated at room temperature for $5 \mathrm{~min}$. The absorbance at $480 \mathrm{~nm}$ was measured on a plate reader. Subtracted the average $480 \mathrm{~nm}$ absorbance measurement of the blank standard replicates from the $480 \mathrm{~nm}$ measurements of all other individual standard and unknown sample replicates. A standard curve was prepared by plotting the average blank-corrected $480 \mathrm{~nm}$ measurement for each BSA standard vs. its concentration in $\mu \mathrm{g} / \mathrm{ml}$. The standard curve was used to determine the protein concentration of each sample.

Equal quantities of protein $(50 \mu \mathrm{g})$ were loaded onto a $10 \%$ SDS gel, resolved using 10\% SDS-PAGE, and transferred to a nitrocellulose membrane for western blot analysis. After blocking the membrane in 5\% milk in $0.1 \%$ TBST for $1 \mathrm{~h}$ at room temperature, the membranes were incubated in diluted primary antibodies $(1: 1,000)$ overnight at $4^{\circ} \mathrm{C}$. Subsequently, the membranes were washed and incubated in HRP-labeled secondary antibodies $(1: 5,000)$ for $1.5 \mathrm{~h}$ at room temperature. SuperSignal West Pico ECL solution (Thermo Fisher Scientific, Inc.) was added to the membranes to enhance the chemiluminescent signal. Protein bands were imaged using a FluorChemE imager (Alpha Innotech). The ImageJ analysis of the western-blot strip grayscale value (band density) was used for relative quantification. Average pixel intensity was obtained following image inversion from black to white pixels using the freeware ImageJ (1.8.0 172; National Institutes of Health).

$R N A$ extraction and reverse transcription-quantitative polymerase chain reaction $(R T-q P C R)$. For $\mathrm{qPCR}$, total RNA was 
extracted using TRIzol ${ }^{\circledR}$ reagent (cat. no. 15596026; Thermo Fisher Scientific, Inc.), and $1 \mu \mathrm{g}$ RNA was used for the RT reaction with random primer (cat. no. 48190011; Thermo Fisher Scientific, Inc.), dNTP mix (cat. no. 18427013; Thermo Fisher Scientific, Inc.) and M-MuLV Reverse Transcriptase (cat. no. M0253L; New England Biolabs). mRNA quantification was performed using a SYBR-Green supermix (cat. no. 1708880; Bio-Rad Laboratories, Inc.). The PCR conditions were as follows: Initial denaturation at $94^{\circ} \mathrm{C}$ for $2 \mathrm{~min}$, followed by 40 cycles of $94^{\circ} \mathrm{C}$ for $30 \mathrm{sec}, 56^{\circ} \mathrm{C}$ for $30 \mathrm{sec}, 72^{\circ} \mathrm{C}$ for $30 \mathrm{sec}$ and $20-60 \mathrm{sec}$ at $72^{\circ} \mathrm{C}$. The triplicate samples were amplified in $20 \mu 1$ reactions with gene-specific primers. The mRNA abundance for each gene of interest was normalized to that of GAPDH. The PCR primers used were as follows: GASC1 forward, 5'-TGGATCCCAGATGCAATGA-3' and reverse, 5'-TGTCTTCAAATCGCATGTCA-3'; NOTCH1 forward, 5'-CCCAATGGGCAAGAAGTCTA-3' and reverse, 5'-CAC AATGTGGTGGTGGGATA-3'; Gli1 forward, 5'-CCTTTA GCAATGCCAGTGACC-3' and reverse, 5'-GAGCGAGCT GGGATCTGTGTAG-3'; Hes1 forward, 5'-AGTGAAGCA CCTCCGGAAC-3' and reverse, 5'-TCACCTCGTTCATGC ACTC-3'; $\beta$-catenin forward, 5'-AAAATGGCAGTGCGT TTAG-3' and reverse, 5'-TTTGAAGGCAGTCTGTCTGA-3'; GAPDH forward, 5'-GAACATCATCCCTGC CTCTACT-3' and reverse, 5'-CGCCTGCTT CACCACCTT-3'.

Animals and treatments. All procedures involving mice were performed with the approval of the Henan University of Science and Technology's Institutional Animal Care and Use Committee and were conducted in accordance with the National Institutes of Health Guide for the Care and Use of Laboratory Animals (19). A total number of 16 (8 male, 8 female) nude mice were used in this study. Upon arrival, at 6 weeks of age, animals were weighed (18-20 g), ear tagged and divided into control, NOTCH inhibitor DAPT, GASC1 inhibitor caffeic acid $(\mathrm{CA})$ and DAPT+CA group $(\mathrm{n}=4)$ following a stratified randomization scheme so that all groups had a similar body weight distribution at the beginning. All mice were housed in type II polycarbonate cages in individually ventilated caging systems with bedding and water and food ad libitum with a standardized NIH-31 diet (cat. no. LAD-NIH-31 diet, Nantong trophic company). Cages were cleaned every week. On those occasions, mice were also examined to evaluate their health. The animal room had a controlled 12/12-h light/dark cycle (lights on at 6:00 am), temperature $\left(22 \pm 2^{\circ} \mathrm{C}\right.$ ) and relative humidity (45-65\%). Food intake was measured by weighing the uneaten pellets. The nude mice were acclimatized for 1 week prior to the start of the experiment.

For the tumor grafting experiment, human glioma tissues were digested and $1 \times 10^{6}$ suspension cells were subcutaneously injected into the flank of nude mice ( $\mathrm{n}=4$ for each groups). Palpable tumors were formed after 6 days. The mice were treated with $15 \mathrm{mg} / \mathrm{kg}$ DAPT (cat. no. D5492; Sigma-Aldrich; Merck KGaA), 100 mg/kg CA (cat. no. 205546; Sigma-Aldrich; Merck KGaA) or both, every 3 days for a total of eight treatments. The treatments were administered via an intraperitoneal injection. Tumor volumes were measured every other day. After the experiment was completed, mice were humanely sacrificed by cervical dislocation following $\mathrm{CO}_{2}$ inhalation. The mouse was placed in the chamber and $100 \% \mathrm{CO}_{2}$ was introduced at a displacement rate of $70 \%$ the chamber volume per min. After a lack of breathing and faded eye color were observed, the mouse was removed from the cage, and cervical dislocation was carried out. Tumor grafts were removed and processed for further analysis. The experiment was carried out for 1 month. The experiment was completed in July and August 2019. No mice died unexpectedly in the experiment.

With regards to humane endpoints, the tumor size must not exceed $20 \mathrm{~mm}(2.0 \mathrm{~cm})$ in any direction in any mice. General criteria for euthanasia include: Weight loss $>20 \%$; tumor size equal to $15 \%$ of body weight; tumor ulceration; discharge or hemorrhage from tumor; tumor interferes with normal body functions, including but not limited to ambulation, eating, drinking, defecation or urination; tumor negatively affects animal's gait or posture independent of tumor size; labored breathing; lack of movement; hypothermia and self-mutilation.

Immunohistochemical staining. Tissue sections were fixed with 10\% neutral buffered formalin (cat. no. DF0111; Beijing Leagene Biotechnology Co., Ltd.) overnight at room temperature followed by embedding in paraffin wax. Section thickness is $5 \mu \mathrm{m}$. Following antigen retrieval and blocking with $10 \%$ goat serum at room temperature for $1 \mathrm{~h}$, tumor tissues were incubated with Ki67, GASC1 and S100 (diluted 1:100) overnight at $4^{\circ} \mathrm{C}$. The slides were then incubated with biotinylated anti-rabbit IgG secondary antibody (cat. no. PK-7200; 1:1,000; Vectastain Elite ABC-HRP kit; Vector Laboratories, Inc.) for $30 \mathrm{~min}$ at room temperature, followed by incubation in Vectastain Elite ABC Reagent for $30 \mathrm{~min}$ at room temperature. For all slides, a diaminobenzidine detection kit (Vector Laboratories, Inc.) was used according to the manufacturer's protocol. For hematoxylin and eosin staining, sections were cleaned with distilled water. Nuclei were stained with Meyer's hematoxylin for $\sim 5$ min then rinsed with tap water and stained with eosin for $2 \mathrm{~min}$ at $37^{\circ} \mathrm{C}$. Cells were rinsed with tap water, dehydrated and mounted. Slides were observed and imaged using a light Nikon ECLIPSE E100 microscope at a magnification of $\mathrm{x} 40$ or $\mathrm{x} 100$.

Invasion Transwell and clonogenic assays. After glioma cells grew to $70-90 \%$ confluence, cells were serum-starved for $24 \mathrm{~h}$ and then diluted at a cell concentration of $1 \times 10^{5}$ cells $/ \mathrm{ml}$. Cell suspension $\left(500 \mu \mathrm{l} ; 5 \times 10^{4}\right.$ cells) was added into the upper Transwell chamber, and $600 \mu 1$ 10\% FBS-DMEM was pipetted into the lower Transwell chamber. Transwell plates were then cultured in the Matrigel-coated inserts in a humidified incubator $\left(37^{\circ} \mathrm{C}, 5 \% \mathrm{CO}_{2}\right)$ for $48 \mathrm{~h}$. Non-migrated cells on the upper side of the membrane were removed using a cotton swab. The cells were then fixed with $1 \mathrm{ml}$ methanol at room temperature for $20 \mathrm{~min}$ and stained with $0.1 \%$ crystal violet for $10 \mathrm{~min}$ at room temperature. In total, six fields per Transwell were imaged using an inverted microscope at x10 magnification, and the migrated cells on the lower site of the membrane were counted. Each condition in the experiment must be performed at least in duplicate.

For the clonogenic assay, after glioma cells grew to $70-90 \%$ confluence, cells were serum-starved for $24 \mathrm{~h}$ and then diluted at a cell concentration of $1 \times 10^{5}$ cells $/ \mathrm{ml}$. Cells were seeded into 6-well plates at a density of 500 cells/well and then cultured for 5 days, followed by crystal violet staining 

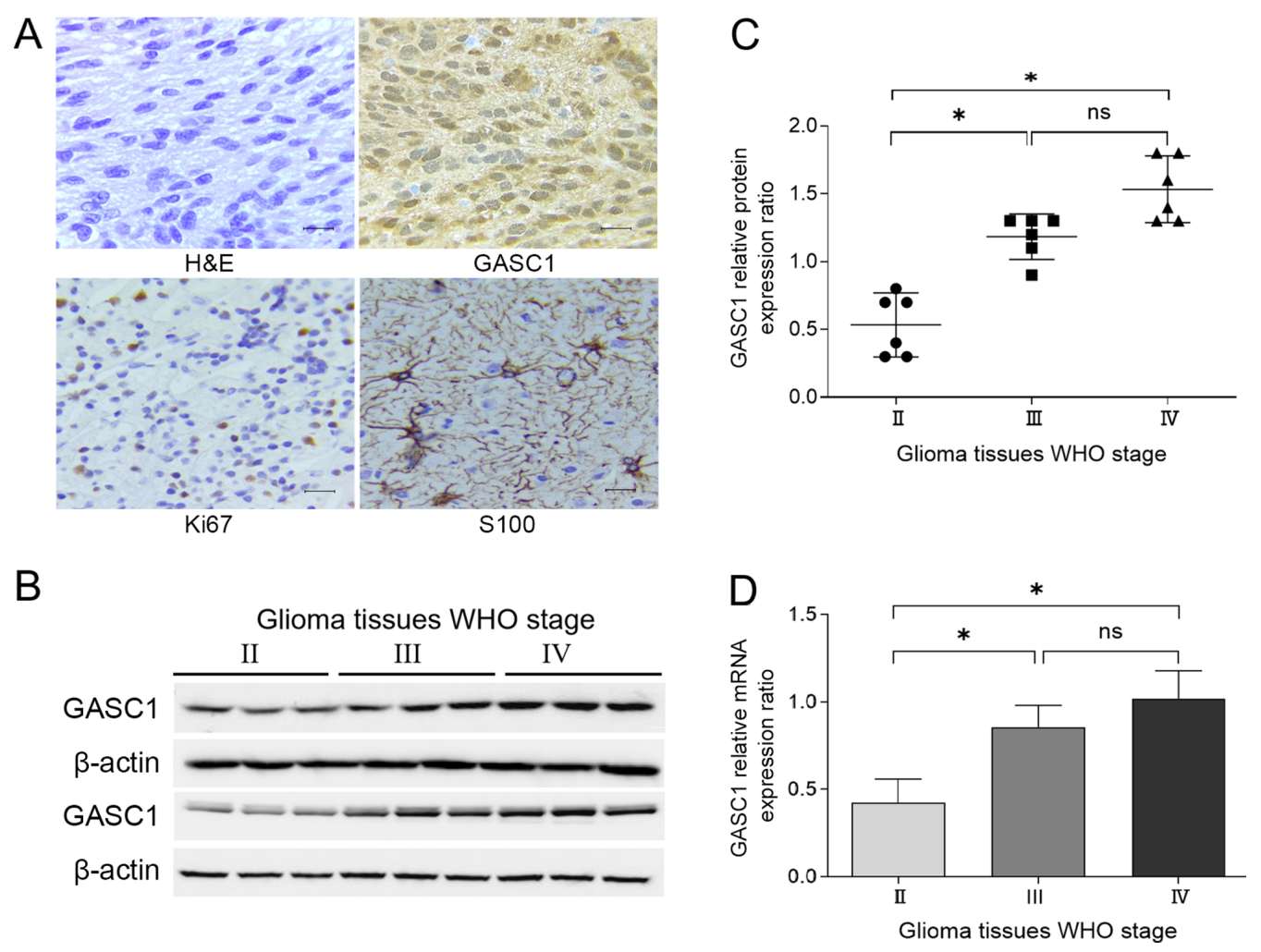

Figure 1. Characterization of GASC1 expression in WHO stage II-IV human glioma samples. (A) Representative images of HE staining and GASC1, cell proliferation marker Ki67 and glial cell marker S100 immunostaining in grade IV glioma tissue (scale bar, $50 \mu \mathrm{m}$ ). Strong immunoreactivity for GASC1 was observed in the nucleus of one repressive glioma sample. (B) Western blotting of the GASC1 expression in WHO stage II-IV glioma tissues. Bands were from two gels, and two internal reference of $\beta$-actin were used. (C) Densitometric semi-quantification of the GASC1 to $\beta$-actin ratio for all WHO stage II-IV samples. Data are expressed as the mean $\pm \mathrm{SD}(\mathrm{n}=3)$. One-way ANOVA followed by Duncan's new multiple range test. (D) mRNA expression levels of GASC1 in glioma tissues were analyzed via reverse transcription-quantitative PCR. Data are presented as the mean \pm SEM ( $n=3$ ). One-way ANOVA followed by the Duncan's new multiple range test, ${ }^{\text {P }}<0.05$. GASC1, gene amplified in squamous cell carcinoma 1; WHO, World Health Organization; ns, non-significant; HE, hematoxylin and eosin.

for $20 \mathrm{~min}$ at room temperature. The cells were washed twice with PBS and the blue colonies were counted using a light Nikon ECLIPSE E100 microscope at a magnification of x10. The data were expressed as \% survival relative to the control. Each condition in the experiment was performed at least in duplicate.

Wound healing assay. Cells $\left(1 \times 10^{5}\right)$ were incubated with $10 \mu \mathrm{g} / \mathrm{ml}$ mitomycin $\mathrm{C}$ at $37^{\circ} \mathrm{C}$ for $2 \mathrm{~h}$, seeded into a 24 -well tissue culture plate and cultured in DMEM/F12 medium containing $10 \%$ FBS (20). After glioma cells grew to $70-80 \%$ confluence a monolayer wound was made by gently and slowly scratching the monolayer with a new 1-ml pipette tip across the center of the well. Following scratching, the well was gently washed twice with medium to remove the detached cells. The well was replenished with fresh serum-starved medium. Cells were cultured for an additional $48 \mathrm{~h}$. the cells were fixed with $4 \%$ paraformaldehyde for $30 \mathrm{~min}$ and stained with $0.1 \%$ crystal violet for $30 \mathrm{~min}$ at room temperature. Images of the stained monolayer were captured on a light Nikon ECLIPSE E100 microscope at a magnification of x10. The same configurations of the microscope were used when capturing images for different views of the stained monolayer. The gap distance was quantitatively evaluated using ImageJ software (1.8.0 172 version; National Institutes of Health), and each experiment was repeated in triplicate.
Sphere formation assay. A total of $1 \mathrm{ml}$ cell suspension $\left(1 \times 10^{3}\right.$ cells) was plated per well in triplicate in a 24 -well Corning ultra-low attachment plate in DMEM/F12 medium, supplemented with $10 \mu \mathrm{g} / \mathrm{ml}$ insulin (Sigma-Aldrich; Merck KGaA), $1 \mu \mathrm{g} / \mathrm{ml}$ hydrocortisone (Sigma-Aldrich; Merck KGaA), 1X B27 (Thermo Fisher Scientific, Inc.), $20 \mathrm{ng} / \mathrm{ml} \mathrm{EGF}, 20 \mathrm{ng} / \mathrm{ml} \mathrm{bFGF}$ and $4 \mu \mathrm{g} / \mathrm{ml}$ heparin (all from Stemcell Technologies, Inc.). After $24 \mathrm{~h}$, parental or NOTCH1-overexpressing CD133 ${ }^{+}$U87 or U251 cells were cultured with GASC1 inhibitor CA $(10 \mu \mathrm{m})$ in the presence or absence of NOTCH1 inhibitor DAPT $(10 \mu \mathrm{m})$ for 7 days to form primary spheres. Cells were nourished every 3 days through the addition of 50-100 $\mu 1$ medium per well. Sphere formation was determined by dividing the total number of spheres by the number of cells plated. Primary sphere assays were performed in at least triplicates.

Statistical analysis. Data analysis was performed using GraphPad Prism 8 software (GraphPad Software,Inc.). An unpaired Student's t-tests were used to compare continuous variables between two groups. One-way ANOVA followed by Duncan's new multiple range test or One-way ANOVA followed by Tukey's post hoc test was used to assess differences between multiple groups. All statistical data were derived from $\geq 3$ independent biological replicates. Data are presented as the mean \pm SD or SEM. $\mathrm{P}<0.05$ was considered to indicate a statistically significant difference. 


\section{Results}

An elevated GASCI expression is associated with malignancy grade and stemness of glioma tissues. Based on certain pathological characteristics, gliomas are classified into four grades (WHO grades I, II, III and IV). Grade I or II tumors are low grade astrocytomas, grade III tumors are anaplastic astrocytomas, and grade IV tumors are glioblastomas multiforme $(21,22)$. To determine the correlation between GASC1 expression levels and clinicopathological parameters in glioma tissues, fresh glioma samples were collected from 18 patients undergoing resection in Neurosurgery Department. There were 6 grade IV, 6 grade III and 6 grade II glioma tissues. Immunohistochemical and hematoxylin and eosin staining was performed on these specimens (Fig. 1A). In the present study, GASC1 expression was primarily immunolocalized in the nuclei and occasionally present in the cytoplasm. Since GASC1 is a nuclear protein, only the GASC1 nuclear expression was analyzed via immunohistochemical staining. The GASC1 protein expression was also examined via western blotting, and higher GASC1 protein expression levels were observed in WHO grade III and IV glioma tissues, as compared to Grade II glioma tissues (Fig. 1B and C). WHO grade III and IV glioma tissues displayed a higher GASC1 nuclear expression compared with Grade II tumors. However, no significant difference in the GASC1 expression levels was identified between WHO grade III and IV glioma tissues (Fig. 1B and C). In addition, in the immunohistochemical staining, a positive GASC1 immunohistochemical nuclear staining and cytoplasm staining was found in all WHO grade III and IV glioma tissues. However, a low level of GASC1 positive staining was observed in the nuclei and cytoplasm of some Grade II tumors. Since GASC1 staining was identified mainly in the nuclei and occasionally in the cytoplasm, the results of the nuclear immunohistochemical staining may be more convincing compared with those of western blotting.

The GASC1 mRNA expression levels were also examined. RT-qPCR analysis demonstrated a higher mRNA expression of GASC1 in grade III and IV glioma tissues compared with grade II tumors (Fig. 1D). In combination, these results indicated that a high malignancy in grade glioma tissue (WHO grade III and IV) was associated with a high GASC1 expression.

In the present study, primary human glioma cells were isolated from human glioma tissues, and GSCs were sorted using CD133 magnetic cell separation. CD133+ isolated cells in the present study formed neurospheres. As confirmed in our previous study (17), the neurospheres can be dissociated and cultured for $\geq 3$ passages. The cells differentiated into cells adherent to the culture plate and grew in a monolayer following culture with regular cell culture medium (Fig. 2A). This observation suggested that $\mathrm{CD} 33^{+}$isolated glioma cells have, at least to some extent, the following cancer stem-like cell properties: Self-renewal and self-differentiation abilities. Following isolation, the GASC1 protein expression was further analyzed, and higher GASC1 protein expression levels were observed in $\mathrm{CD} 133^{+}$ isolated primary culture human glioma cells, as compared with their parental cells (Fig. 2B). As expected, RT-qPCR results identified significant differences in the GASC1
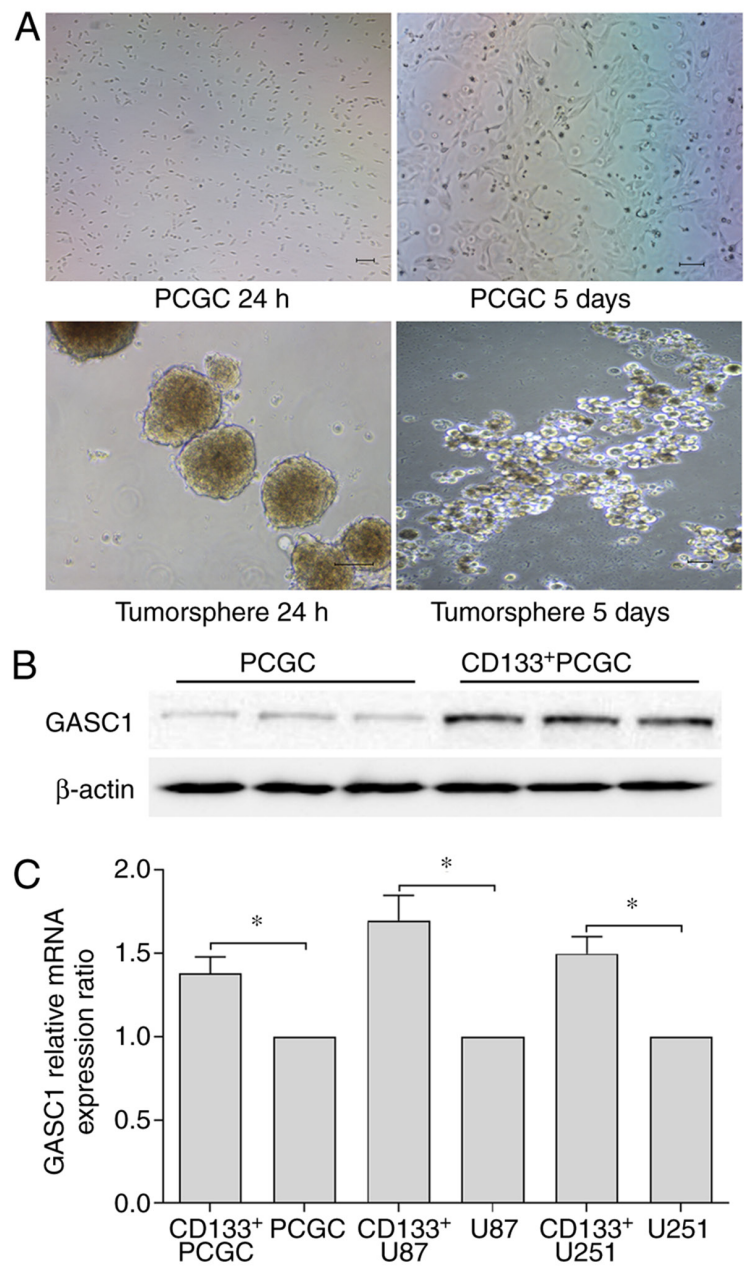

Figure 2. Characterization of PCGCs and $\mathrm{CD}_{133^{+}} \mathrm{PCGC}$ spheres (A) Representative microscopic images of PCGCs and tumorspheres of $\mathrm{CD}_{133^{+}}$PCGCs (scale bar, $50 \mu \mathrm{m}$ ). Fresh primary glioma samples were dissociated and propagated as non-adherent neurospheres in serum-free defined medium. (B) Western blotting of GASC1 expression in $\mathrm{CD}_{133^{+}}$or parental PCGC. A higher GASC1 protein expression was observed in the CD133+ PCGC. (C) Reverse transcription-quantitative polymerase chain reaction of GASC1 mRNA expression levels in $\mathrm{CD}_{133^{+}}$or parental U87, U251 and PCGC. Data are expressed as the mean \pm SEM $(n=3)$. Unpaired Student t-test, ${ }^{*} \mathrm{P}<0.05$. ns, non-significant; PCGC, primary culture human glioma tissue cells; GASC1, gene amplified in squamous cell carcinoma 1.

mRNA expression levels between the $\mathrm{CD} 133^{+}$isolated glioma cells and their parental primary culture human glioma cells (Fig. 2C). Moreover, higher mRNA expression levels of $\mathrm{CD} 133^{+} \mathrm{U} 87$ and U251 were observed in glioma cells, as compared with their parental cells (Fig. 2C). These results indicated that the GASC1 protein may be associated with glioma stemness.

GASCl inhibition suppresses the viability and migration of glioma cells. To further investigate the association between GASC 1 expression and glioma progression, a CCK-8 assay was used to examine the effect of the GASC1 inhibition on the viability of primary culture human glioma cells. GASC1 was knocked down using shRNA, and this significantly decreased the viability of primary culture human glioma cells after $48 \mathrm{~h}$ (data not shown). The invasive and migratory abilities of primary culture human glioma cells were examined using an invasion chamber assay and a wound healing test 
A
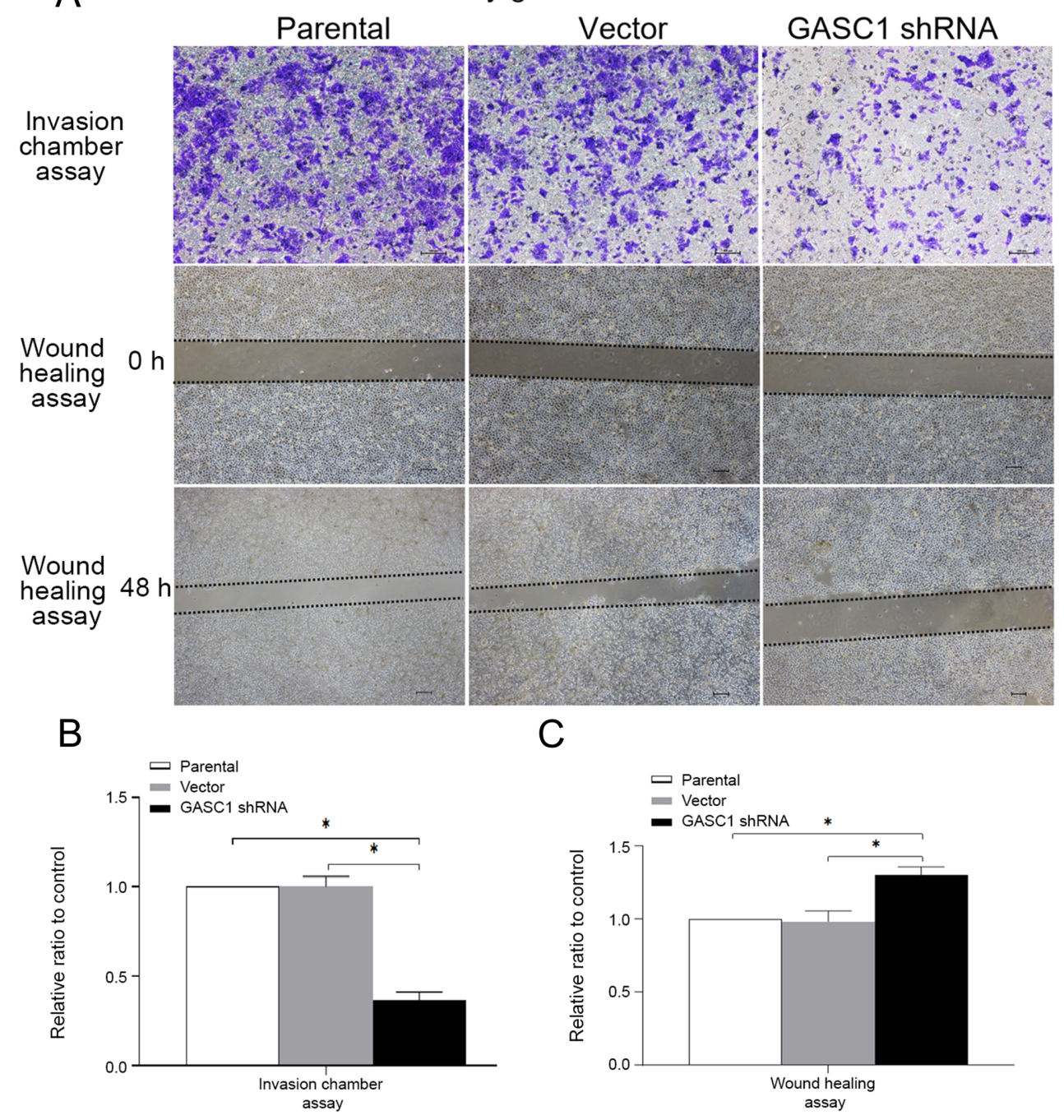

Figure 3. GASC1 inhibition suppresses invasion and metastasis ability in CD133+ U87 or U251 glioma stem-like cells. (A) Invasion chamber assay and wound healing migration assay for PCGCs with or without GASC1-knockdown. For the invasion chamber assay, a hollow plastic chamber sealed at one end with a porous membrane was suspended over a larger well containing cell culture medium. Cells were placed inside the chamber and allowed to migrate through the pores to the other side of the membrane for $48 \mathrm{~h}$. Migratory cells were then stained and counted. For the wound healing migration assay, cells were plated in 24-well plates after they grew to 70-90\% confluence. A scratch wound was made using a same pipette tip. The medium was replaced, and the wounds were imaged at 48 h. (B) The relative fractions for invasion and (C) migration detection in GASC1-specific shRNA, vector and control cells were plotted. Data are expressed as the mean \pm SD $(n=3)$. Unpaired Student t-test, ${ }^{*} \mathrm{P}<0.05$. ns, non-significant; GASC1, gene amplified in squamous cell carcinoma 1 ; shRNA, short hairpin RNA.

(Fig. 3A and B). The results demonstrated that the invasive and migratory abilities of GASC1-knockdown primary culture human glioma cells were significantly suppressed compared with the control.

GASC1 inhibition suppresses the clone forming ability and tumorsphere formation in CD133+ U87 or U251 glioma stem-like cells. The effect of GASC1-knockdown on CD133+ GSCs was further analyzed. First, the U87 or U251 cells were transiently transfected with GASC1 shRNA for the clone formation assay. A lower clone forming ability was observed in U87 or U251 cells with GASC1 shRNA (Fig. 4A and D). Furthermore, the CD133+ U87 or CD133+ U251 cells were transiently transfected with GASC1 shRNA and examined with a tumorsphere assay and flow cytometry (Fig. 4B, C, E and F). As expected, a decreased tumorsphere forming ability, increased apoptotic rate and G1 phase accu- mulation were observed in GASC1-knockdown CD133+ U87 or $\mathrm{CD} 133^{+} \mathrm{U} 251$ cells, as compared with the relative control group. Collectively, these results demonstrated that GASC1 inhibition suppresses the viability and stemness of glioma cells.

GASC1 inhibition-mediated suppression of cancer cell viability is dependent on NOTCHI activation. It is known that GSCs upregulate a number of signaling pathways required for maintaining glioma stemness; these signaling pathways include the NOTCH, sonic hedgehog (Shh) and Wnt pathways $(15,23)$. To understand the mechanism underlying the anti-stemness of glioma cells caused by GASC1-knockdown, the key markers of the specific pathways that are required for maintaining GSC stemness, including Gli1 (Shh), Hes1 (NOTCH) and $\beta$-catenin (Wnt) (23-26), were examined in control and GASC1-knockdown cells. Our results have shown 

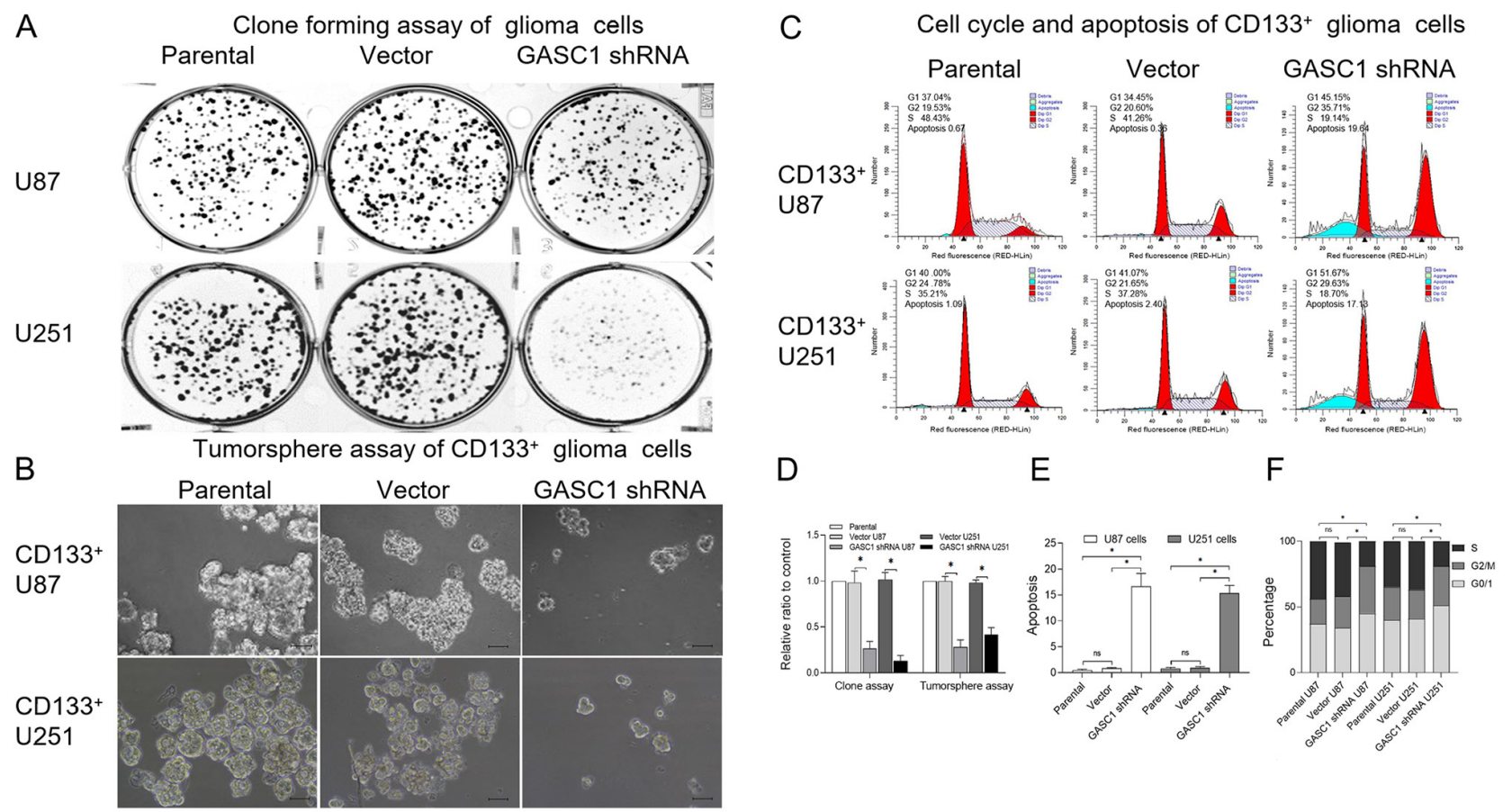

Figure 4. GASC1 inhibition suppresses the clone forming ability and tumorsphere formation in $\mathrm{CD}_{133^{+}} \mathrm{U} 87$ or $\mathrm{U} 251$ glioma stem-like cells. (A) Clonogenic assays examining the effects of GASC1-knockout on cell proliferation in U87 or U251 glioma cells with or without GASC1-knockdown. Cells were seeded into 6-well plates at a density of 500 cells/well and then cultured for 5 days, followed by crystal violet staining. (B) Tumorsphere assay of GASC1-knockout on $\mathrm{CD} 133^{+} \mathrm{U} 87$ or U251 glioma cells with or without GASC1-knockdown (scale bar, $100 \mu \mathrm{m}$ ). Single cells from tumorspheres were seeded at a density of 20,000 cells $/ \mathrm{ml}$ in a $10 \mathrm{ml} \mathrm{GSC}$ growth medium in a $10-\mathrm{cm}$ culture dish. The cells were incubated at $37^{\circ} \mathrm{C}, 5 \% \mathrm{CO}_{2}$ for 5 days to generate bulk cultured tumorspheres. (C) Representative flow cytometry images of cell cycle distribution and apoptosis in CD133+ U87 or U251 glioma cells with or without GASC1-knockdown. (D) Quantitative analysis for stained colonies and tumorspheres in different group panels. shRNA-mediated GASC1 silencing significantly decreased the cloning ability of U87 or U251 glioma cells and the tumorsphere formation ability of CD133 ${ }^{+} \mathrm{U} 87$ or U251 glioma cells. Data are expressed as the mean $\pm \mathrm{SD}\left(\mathrm{n}=3\right.$ ). Unpaired Student t-test, ${ }^{\mathrm{P}}<0.05$. (E) Quantification of the percentage of G0/1, G2/M and S cells in CD133 ${ }^{+} \mathrm{U} 87$ or U251 glioma cells with or without GASC1-knockdown. Data are expressed as the mean $\pm \mathrm{SEM}(\mathrm{n}=3)$. Unpaired Student t-test, ${ }^{\prime} \mathrm{P}<0.05$. (F) Quantification of the percentage of apoptosis

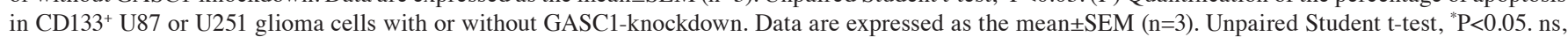
non-significant; GASC1, gene amplified in squamous cell carcinoma 1; shRNA, short hairpin RNA.

that GASC1-knockdown downregulated the expression levels of Gli1, Hes1 and active $\beta$-catenin (Fig. 5A), suggesting that all three pathways were affected in the $\mathrm{CD} 133^{+} \mathrm{U} 87$ or U251 cells following GASC1-knockdown. Moreover, Our mRNA analysis has shown that the Hes1 gene from the NOTCH1 pathway was downregulated to the greatest extent (Fig. 5B). These results indicated that the NOTCH1 pathway may be the main mediator of GASC1-knockdown on the $\mathrm{CD}^{133^{+}} \mathrm{U} 87$ or U251 cells.

To determine whether NOTCH1 participates in the regulation of the stemness of gliomas by GASC1, NOTCH1 overexpression vectors were successfully constructed. The parental or NOTCH1-overexpressing CD133 ${ }^{+} \mathrm{U} 87$ or U251 cells were cultured with GASC1 inhibitor CA $(10 \mu \mathrm{m})$ for $48 \mathrm{~h}$ for the tumorsphere assay. Furthermore, the cells were treated with GASC1 inhibitor CA $(10 \mu \mathrm{m})$ in the presence or absence of NOTCH1 inhibitor DAPT $(10 \mu \mathrm{m})$ for $48 \mathrm{~h}$, and the individual tumorspheres were then scored. The results demonstrated that the blockade of GASC1, including GASC1-knockdown and CA treatment, significantly decreased the key NOTCH1 target Hes1 protein and mRNA expression levels. NOTCH1-overexpression was found to partly abrogate the GASC1 inhibitor CA-induced inhibition of tumorsphere formation (Fig. 5C). By contrast, the NOTCH1 inhibitor DAPT enhanced the suppressive effect of the GASC1 inhibitor on the tumorsphere forming ability of $\mathrm{CD} 133^{+} \mathrm{U} 87$ or U251 cells (Figs. 5C and S1). Furthermore, western blotting demonstrated that NOTCH1-overexpression partially reversed the CA-induced cyclin D1 and Ki67 inhibition (except for in U87 cells) and Bax upregulation, as compared with the Notch1+ and CA+Notch1+ group (Fig. 5D-F). Moreover, CA decreased the NOTCH1, cyclin D1 and Ki67 expression levels, while increased the Bax expression. NOTCH1 overexpression partially reversed CA-induced Bcl-2, cyclin D1 and Ki67 downregulation (except for in U87 cells) and Bax upregulation in $\mathrm{CD}_{133^{+}} \mathrm{U} 87$ or U251 glioma cells. Collectively, these results demonstrated that the ability of GASC1 inhibition to suppress the viability of glioma cells is dependent, at least in part, on the activity of NOTCH1.

Inhibition of GASCI/NOTCH1 signaling suppresses the progression of glioma tumor-bearing mice. To evaluate the effects of the GASC1/NOTCH1 signaling activity on the growth of glioma in vivo, human glioma primary culture cells were inoculated under the skin of nude mice to generate a tumor-bearing mouse model. The mice were treated with NOTCH inhibitor DAPT $(15 \mathrm{mg} / \mathrm{kg})$, GASC1 inhibitor CA $(100 \mathrm{mg} / \mathrm{kg})$ or both, every 3 days for a total of eight treatments. Tumor measurement and Ki67 staining showed that both DAPT and CA suppressed tumor growth, and a combination of the two decreased tumor growth more significantly, as compared with either treatment alone (Fig. 6). However, no significant differences were observed 
A

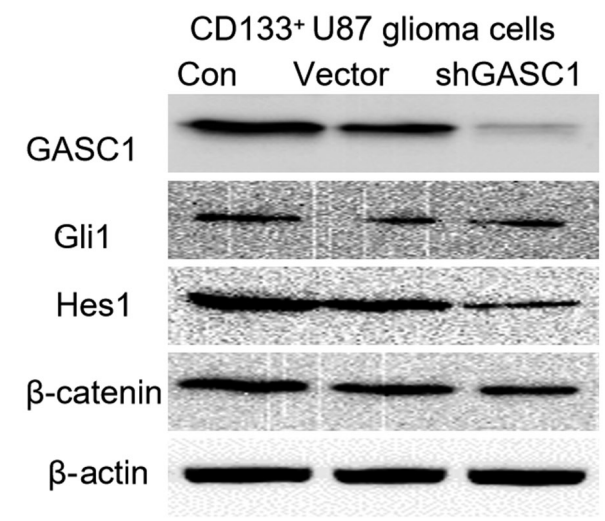

\section{B}

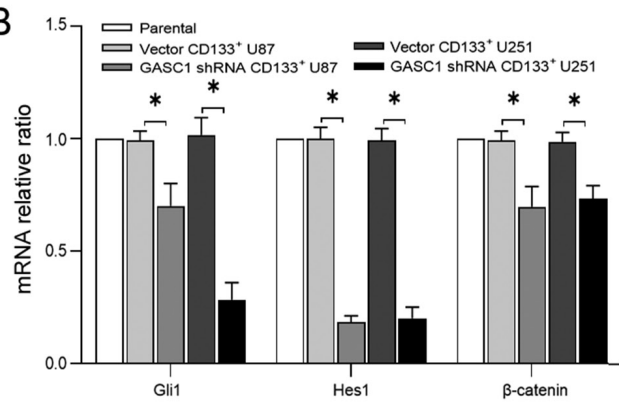

D

CD133+ U87 glioma cells

Con $\mathrm{CA} \quad \mathrm{NOTCH} 1^{+} \mathrm{CA}+\mathrm{NOTCH} 1^{+}$
C

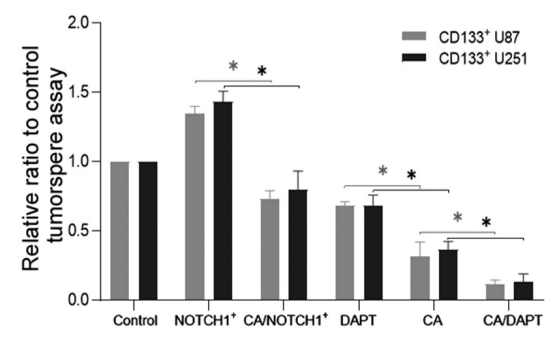

CD133+ U251 glioma cells

$\mathrm{CA} \mathrm{NOTCH}_{1}{ }^{+} \mathrm{CA}+\mathrm{NOTCH}{ }^{+}$

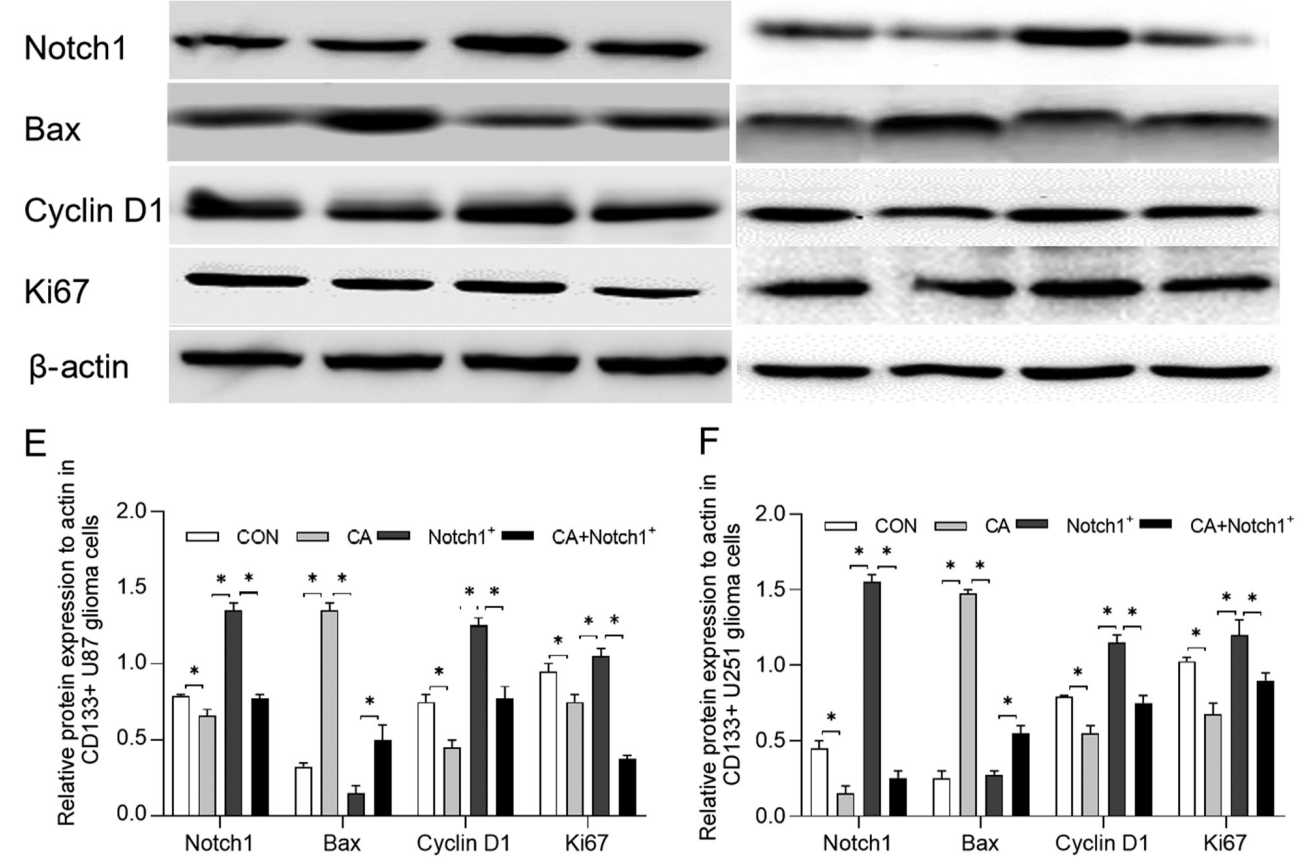

Figure 5. Effect of GASC1 inhibition on key markers of GSC stemness-related signaling pathways. (A) Protein expression levels of key markers of GSC stemness-related signaling pathways, such as Gli1 (Shh), Hes1 (NOTCH) and $\beta$-catenin (Wnt) in GASC1-knockdown or vector CD133+ U87 or U251 glioma cells. Decreased Gli1, Hes1 and $\beta$-catenin protein expression levels were observed in GASC1-knockdown CD133+ U87 glioma cells. (B) GASC1-knockdown decreased Gli1, Hes1 and $\beta$-catenin mRNA expression levels in CD133+ U87 or U251 glioma cells. One-way ANOVA followed by Tukey's post hoc test. (C) Effect of GASC1 inhibitor CA, NOTCH1 inhibitor DAPT and NOTCH1 overexpression on the tumorsphere formation ability of CD133 ${ }^{+}$U87 or U251 glioma cells. The parental or NOTCH1-overexpressing CD133+ $\mathrm{U} 87$ or U251 cells were cultured with GASC1 inhibitor CA $(10 \mu \mathrm{m})$ for $48 \mathrm{~h}$ for the tumorsphere assay. The CD133+ $\mathrm{U} 87$ or U251 cells were also treated with GASC1 inhibitor CA $(10 \mu \mathrm{m})$ in the presence or absence of NOTCH1 inhibitor DAPT $(10 \mu \mathrm{m})$ for $48 \mathrm{~h}$, followed by the tumorsphere assay. NOTCH1-overexpression partly abrogated the CA-induced tumorsphere formation inhibition. NOTCH1 inhibitor DAPT enhanced the suppressive effect of the GASC1 inhibitor on the tumorsphere formation of $\mathrm{CD} 133^{+} \mathrm{U} 87$ or $\mathrm{U} 251$ cells. Data are expressed as the mean $\pm \mathrm{SD}$ $(\mathrm{n}=3)$. Unpaired Student t-test, ${ }^{*} \mathrm{P}<0.05$. (D) Following overnight serum-starvation, CD133+ ${ }^{+} 87$ or U251 glioma cells transiently transfected with vector control or NOTCH1-overexpression were stimulated with $\mathrm{CA}(10 \mu \mathrm{M})$ for $48 \mathrm{~h}$ and the cells were harvested for western blotting using the indicated antibodies. CA decreased the NOTCH1, cyclin D1 and Ki67 expression levels, while increased the Bax expression. NOTCH1 overexpression partially reversed CA-induced Bcl-2, cyclin D1 and Ki67 downregulation (except in U87 cells) and Bax upregulation in CD133 ${ }^{+}$U87 or U251 glioma cells. Semi-quantification of NOTCH1, Bax, cyclin D1 and Ki67 protein expression levels in (E) CD133 ${ }^{+} \mathrm{U} 87$ and (F) U251 glioma cells treated with vector control, CA, NOTCH1-overexpression or CA combined with NOTCH1-overexpression. Data are expressed as the mean $\pm \mathrm{SD}(\mathrm{n}=3)$. One-way ANOVA followed by Tukey's post hoc test. "P<0.05. GASC1, gene amplified in squamous cell carcinoma 1; CA, caffeic acid; NOTCH1, notch receptor 1. 


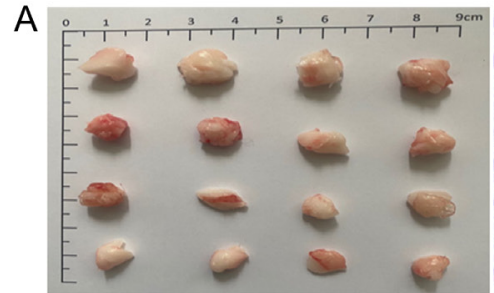

Xenofrafts

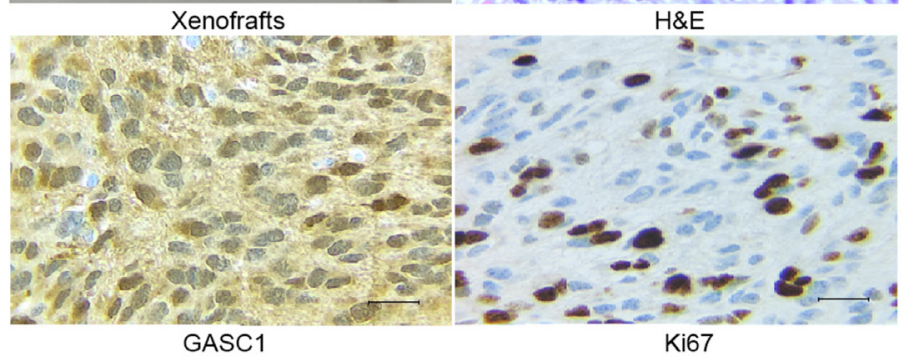

GASC1

B

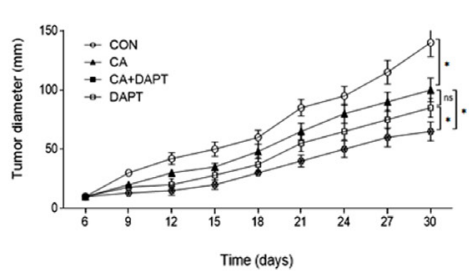

C

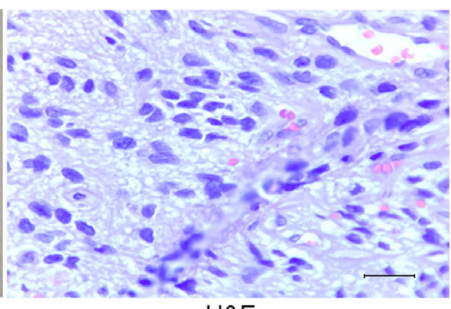

Ki67

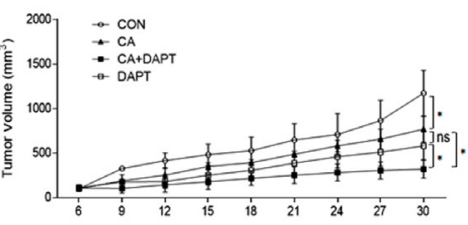

Time (days)

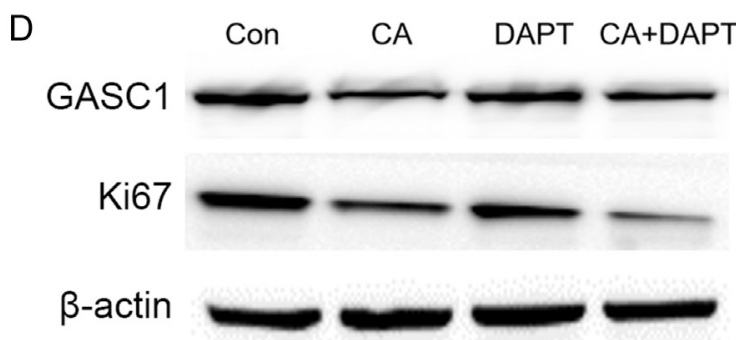

Figure 6. CA and DAPT decreases the growth of human glioma xenografts synergistically. (A) Histopathologic features of the human glioma xenografts, HE staining and immunohistochemistry for GASC1 and Ki67 expression in primary cultured human glioma cell xenograft tissues from mice (scale bar, $50 \mu$ m). Primary cultured human glioma cells were implanted in the flanks of the mice $(n=16)$ and the tumors were allowed to develop to an appreciable size for 6 days $\left(60-80 \mathrm{~mm}^{3}\right)$. Next, CA $(100 \mathrm{mg} / \mathrm{kg})$, DAPT $(15 \mathrm{mg} / \mathrm{kg})$ or both, were injected intraperitoneally beginning on day 6 and were administered every 3 days for a total of eight treatments. The average (B) diameter and (C) volume was calculated at the indicated time points. Both DAPT and CA suppressed tumor growth, and the combined use of DAPT and CA decreased tumor growth more significantly than either treatment alone. Data are presented as the mean \pm SD. One-way ANOVA followed by Tukey's post hoc test, ${ }^{*} \mathrm{P}<0.05$. (D) Western blotting of GASC1 and Ki67 expression in xenograft tissues of different groups. GASC1, gene amplified in squamous cell carcinoma 1; CA, caffeic acid; ns, non-significant; HE, hematoxylin and eosin; CON, control.

between treatment with DAPT and CA alone. Western blotting showed that the expression of Ki67 was decreased in the tumor tissues of DAPT- or CA-treated mice, with the most significant effect observed in the DAPT+CA-treated mice. The differences in tumor volume between the control and DAPT+CA-treated mice were statistically significant. These data suggested that GASC1-NOTCH1, at least to some extent, contributed to the development of glioma in vivo and may serve as potent therapeutic targets for the control of gliomas.

\section{Discussion}

Epigenetics are alterations in gene expression without changes in the DNA sequence (27). Since epigenetic changes have long been documented to govern a variety of cellular processes, including gene expression, DNA replication and stem cell maintenance, aberrant epigenetic modifications can cause abnormal gene silencing or activation leading to disease, such as cancer and mental disorders (28). To date, several epigenetic studies have identified a large number of tumor suppressor genes silenced in glioblastoma, such as dickkopf WNT signaling pathway inhibitor 1 (DKK1) and frizzled-related protein 1 (SFRP1) $(29,30)$. Thus, epigenetic modifications have been proposed to be potential prognostic and response factors for glioblastoma treatment $(31,32)$. Since epigenetic silencing of tumor suppressor genes is reversible, there is extensive interest in developing inhibitors against DNA methyltransferases and histone deacetylases (33). Thus, finding key molecular targets that lead to tumoriogenesis and discovering more specific inhibitors of histone deacetylases and histone methyltransferases may need to be considered in future diagnostics and treatment for glioblastoma.

Recently, epigenetic research has provided several important histone modifier genes. One of the most clinically 
relevant observations was the discovery of GASC1 (10). As a member of the JMJD2 family, GASC1 is located at human chromosome 9p23-24 and encodes a histone demethylase for $\mathrm{H} 3 \mathrm{~K} 9 \mathrm{me} 3 / 2$ and H3K36me3/2 (5-7). H3K9me3/2 mark is associated with transcriptional repression and the formation of heterochromatin, while $\mathrm{H} 3 \mathrm{~K} 36 \mathrm{me} 3 / 2$ is involved in the suppression of incorrect transcription (34). Since GASC1 can either remove the repressive $\mathrm{H} 3 \mathrm{~K} 9 \mathrm{me} 3 / 2$ or the active $\mathrm{H} 3 \mathrm{~K} 36 \mathrm{me} 3 / 2$ factor in modifying the $\mathrm{H} 3$ process, GASC1 has been reported to promote proliferation and survival in various cancer cells by activating several classical oncogenes, such as MYC, NOTCH1, SOX2 and MDM2 proto-oncogene (MDM2) (7-14). For example, GASC1 overexpression in the non-tumorigenic breast cell line MCF10A induces transformed phenotypes $(6,7)$, while GASC1-knockdown in skin squamous cell carcinoma and breast cancer cells inhibits proliferation $(6,7,9,11)$.

GASC1 can also crosstalk with other molecules to promote carcinogenesis, as previous studies indicated that GASC1 can cooperate with JAK2 to modify the epigenome of 9p24-amplified lymphomas and promote proliferation and survival (35-37). Since GASC1 expression is identified in $>50 \%$ of gliomas $(8,12)$, it is highly likely that GASC1 contributes to the genesis and/or development of glioma. There was direct evidence in the present study of a higher expression of the GASC1 in the WHO grade III and IV glioma tissues. It was also found that the inhibition of GASC1/NOTCH signaling significantly suppressed the viability, migration and stemness of glioma cells. Thus, the present data indicated that GASC1 has the potential to serve as a valuable prognostic biomarker, and could facilitate the development of personalized therapies targeting GASC1/NOTCH signaling as an innovative treatment for glioma in the future.

It is known that GSCs are responsible for cancer progression and recurrence, and the elimination of GSCs is crucial for treating glioblastoma $(38,39)$. To the best of our knowledge, the association between GASC1 expression and the clinical progression of glioma remains unknown. Thus, further studies are required to understand the biological features of GASC1 in gliomas and GSCs. In the present study, the function and mechanism of GASC1 in the proliferation, invasion and stemness of glioma cells was analyzed. In line with a previous study (12), GASC1 expression was found in most glioma tissues. Moreover, for the first time, a higher GASC1 expression was identified in WHO grade III and IV glioma tissues, as compared with the Grade II glioma tumor tissues. Although the statistical association between the GASC1 expression and poor prognosis has not been confirmed, the present data suggested that high-grade gliomas tend to express GASC1, suggesting that the GASC1 expression may be associated with glioma malignancy. In the present study, GASC1 inhibition suppressed the viability, invasion and stemness of glioma cells. Further mechanistic studies demonstrated that GASC1 affected the stemness of gliomas by modifying the activity of the NOTCH, Shh and Wnt signaling pathways, with the most significant effect observed in the NOTCH1 mRNA expression levels. In addition, the present in vivo data demonstrated the suppressive effect of a GASC1 inhibitor on the viability of glioma cells in xenograft tumors. These experiments suggested a pro-tumorigenesis role of GASC1 in the development of gliomas in vitro and in vivo. The results also indicated that a GASC1 inhibitor could be a potential molecular therapeutic agent in the control of gliomas.

NOTCH signaling is a key well-known player in cell proliferation, apoptosis, stem cell maintenance and tissue homeostasis (26,40-42). GSCs have been found to exhibit higher NOTCH1 expression levels $(42,43)$. The NOTCH1 pathway serves a vital role in GSC maintenance (44). Moreover, NOTCH1 has been suggested to mediate in chemotherapeutic resistance and tumor recurrence by crosstalk with other molecules. Since NOTCH1 signaling activates downstream Hes1, Hes1 is recognized as a biomarker of NOTCH1 pathway activation $(26,45)$. NOTCH1 can regulate several target genes, such as p53, EGFR and PTEN, in mediating the PI3K/AKT/mTOR pathway $(26,41,45)$. Moreover, the molecular mechanism and crosstalk of NOTCH1 in glioma-initiating cells was also reported. HIF-1-depletion can block the interaction between HIF-1 $\alpha$ and Notch intracellular domain (NICD), and suppress GSC proliferation (46). HIF-1 $\alpha$ can also displace the NOTCH inhibitor HIF-2 $\alpha$ from the NICD under hypoxic conditions (47). Currently, most NOTCH inhibitors remain in clinical phase I and II trials, but several NOTCH inhibitors had only a modest efficacy in the initial stage, with an unsatisfactory outcome $(48,49)$. Since the tumor microenvironment contains a complex mixture of biochemical and biophysical cues that modulate cell behavior $(33,50)$, possible reasons for these unsatisfied results may have been the heterogeneity of glioma and the crosstalk between the NOTCH pathway and other molecules.

In the present study, GASC1 inhibition decreased NOTCH1 expression, which was in line with previous studies (14,37). The present data suggested that GASC1 may be one of the major factors affecting NOTCH1 activity. Besides NOTCH1, the current data revealed that GASC1 also affects the Shh and Wnt signaling pathways. In support of this notion, previous studies reported that GASC1 can regulate numerous other molecules, such as MYC, NOTCH1, SOX2, MDM2, JAK2, peroxisome proliferator activated receptor gamma, Nanog homeobox and HIF-1 $\alpha$ in cancer cells $(5-14,35,51)$. All the data suggested that GASC1 may regulate NOTCH1 and other signaling pathways to control the viability, migration and stemness of cancer cells.

To date, neither NOTCH inhibitors nor siRNA clinical trials have elicited satisfactory results, which suggests that a complex network of multiple signals on different regulatory levels controls cancer cell behavior (49). Another possible reason for this trait may be the low delivery efficiency of siRNA particles or inhibitors to the specific irregular cells (13). Since epigenetic processes and changes are so widespread, it is necessary to specifically target abnormal cells with minimal damage to normal cells. On this issue, a recent study revealed that nanobioconjugates of GASC1 siRNA and nanoparticles significantly increased the therapeutic growth inhibition of GASC1-knockdown in basal-like breast cancer cells (13). This study showed promise for the possible therapeutic application of siRNA in future clinical application.

Cancer cells can communicate with stromal cells, including osteoblastic cells, adipocytic cells, macrophages, fibroblasts and other immune cells $(52,53)$. Cancer cells can also influence the microenvironment cells to promote pathways that benefit 
the cancer cells, such as EGFR and NOTCH1 signaling pathways (33). GASC1 has been reported to be regulated by IL-6 (5), suggesting that GASC1 can communicate with other signaling pathways. It is therefore necessary to conduct high-through-put analysis of GASC1/NOTCH1 signaling in the development of glioma. It is known that Wnt signaling and Shh signaling pathways are among the major pathways aberrantly activated in human glioma tissues (54). The World Health Organization 2016 classification of central nervous system described that $10 \%$ of the medulloblastomas were Wnt activated tumors, and 30\% of the medulloblastomas were Shh activated (55). In the present study, besides the NOTCH1 signaling, the Shh and Wnt pathways were also inhibited by GASC1 knockdown, which, to the best of our knowledge, has not been previously reported. However, further research is required to examine the influence of GASC1 on the Shh and Wnt signaling.

There were numerous inherent limitations in the present study. The most important one was the small number of enrolled patients. This limited the ability to determine the significance of the GASC1 difference in survival among the various malignant stage group patients. The present study found no statistically significant association between the GASC1 expression and the glioma malignancy stages III and IV. This result does not rule out the possible role of GASC1 in glioma progression. The results need to be confirmed in a larger number of patients for a longer treatment period before the overall role of GASC1 in the progression of glioma can be completely verified. Due to the great variation in the transfection efficiency of GSCs from different patients, U87 glioma cells were used to isolate GSCs to obtain homogeneity. Previous data have suggested several cell markers for GSCs; among them, $\mathrm{CD}_{133^{+}}$cells in glioblastoma display cancer stem cell-like properties and CD133 is known to be highly expressed in GSCs $(15,56)$. However, more rigorous research will be required to establish whether CD133 is an effective marker of GSCs. There is a need to define CSCs using more precise functional markers to improve the purity and stemness of the isolated GSCs. In addition, the present study only recorded the diameter of the xenografts, and the weight of the tumors was not tested in this study. This has to some extent undermined the significance of the current in vivo experiments, which should be improved in future research.

In conclusion, the present study provided evidence that GASC1 signaling was highly activated in WHO grade III and IV glioma tissues. This finding was in line with previous studies showing that $>50 \%$ of gliomas exhibit a higher GASC1 expression $(30,57,58)$. The data from the current and previous studies also indicated that GASC1 can regulate NOTCH1 signaling in glioma tissues and is enriched in GSCs $(14,59)$. Thus, GASC1 may coordinate with several other signaling molecules to rapidly and transiently activate NOTCH1 signaling and mediate stemness maintenance in GSCs. Subsequently, the present study demonstrated that GASC1/NOTCH1 downregulation could significantly inhibit the growth of glioma cells and GSCs in vitro and in vivo. The current research elucidated a novel mechanism of GASC1-mediated glioma carcinogenesis and provided new perspectives for the therapeutic targets of GASC1/NOTCH1 axis in the clinical treatment of glioma. Since epigenetic modifiers occur frequently in gliomas $(31-33,60)$, further studies are required to determine the detailed GASC1/NOTCH1 signaling network, in order to develop possible specific markers and therapeutic targets that are effective in treating glioma.

\section{Acknowledgements}

Not applicable.

\section{Funding}

The present study was supported by the funding from The National Natural Science foundation of China (grant no. U1404822).

\section{Availability of data and materials}

The datasets used and/or during the present study are available from the corresponding author upon reasonable request.

\section{Authors' contributions}

ZX designed the study and wrote the manuscript. XBW, KZ and $\mathrm{ZhL}$ supervised the study, contributed to data acquisition and revised the manuscript. XY, ZS, CJS and ZL collected and analyzed the data and conducted the experiments. ZX, XBW, $\mathrm{KZ}, \mathrm{ZhL}, \mathrm{XY}, \mathrm{ZS}$, CJS and ZL confirmed the authenticity of all the raw data. All authors read and approved the manuscript and agreed to be accountable for all aspects of the research in ensuring that the accuracy or integrity of any part of the work were appropriately investigated and resolved.

\section{Ethics approval and consent to participate}

This study was approved by The First Affiliated Hospital of Henan University of Science and Technology Institutional Review Board (approval no. 2013-08). Written informed consent was obtained from each donor and patient. All procedures involving mice were approved by the Henan University of Science and Technology Institutional Animal Care and Use Committee and were performed in accordance with the National Institutes of Health Guide for the Care and Use of Laboratory Animals, 8th edition. Washington (DC): National Academies Press (US); 2011.

\section{Patient consent for publication}

Not applicable.

\section{Competing interests}

The authors declare that they have no competing interests.

\section{References}

1. Ostrom QT, Cote DJ, Ascha M,Kruchko C and Barnholtz-Sloan JS: Adult glioma incidence and survival by race or ethnicity in the United States from 2000 to 2014. JAMA Oncol 4: 1254-1262, 2018. 
2. Yang P, Wang Y, Peng X, You G, Zhang W, Yan W, Bao Z, Wang Y, Qiu X and Jiang T: Management and survival rates in patients with glioma in China (2004-2010): A retrospective study from a single-institution. J Neurooncol 113: 259-266, 2013.

3. Zhao YD, Zhang QB, Chen H, Fei XF, Shen YT, Ji XY, Ma JW, Wang AD, Dong J, Lan Q, et al: Research on human glioma stem cells in China. Neural Regen Res 12: 1918-1926, 2017.

4. Li K, Lu D, Guo Y, Wang C, Liu X, Liu Y and Liu D: Trends and patterns of incidence of diffuse glioma in adults in the United States, 1973-2014. Cancer Med 7: 5281-5290, 2018.

5. Cloos PA, Christensen J, Agger K, Maiolica A, Rappsilber J, Antal T, Hansen KH and Helin K: The putative oncogene GASC1 demethylates tri- and dimethylated lysine 9 on histone $\mathrm{H} 3$. Nature 442: 307-311, 2006.

6. Liu G, Bollig-Fischer A, Kreike B, van de Vijver MJ, Abrams J, Ethier SP and Yang ZQ: Genomic amplification and oncogenic properties of the GASC1 histone demethylase gene in breast cancer. Oncogene 28: 4491-4500, 2009.

7. Berdel B, Nieminen K, Soini Y, Tengström M, Malinen M, Kosma VM, Palvimo JJ and Mannermaa A: Histone demethylase GASC1 - a potential prognostic and predictive marker in invasive breast cancer. BMC Cancer 12: 516, 2012.

8. Sun LL, Holowatyj A, Xu XE, Wu JY, Wu ZY, Shen JH, Wang SH, Li EM, Yang ZQ and Xu LY: Histone demethylase GASC1, a potential prognostic and predictive marker in esophageal squamous cell carcinoma. Am J Cancer Res 3: 509-517, 2013.

9. Uimonen K, Merikallio H, Pääkkö P, Harju T, Mannermaa A, Palvimo J, Kosma VM and Soini Y: GASC1 expression in lung carcinoma is associated with smoking and prognosis of squamous cell carcinoma. Histol Histopathol 29: 797-804, 2014

10. Kupershmit I, Khoury-Haddad H, Awwad SW, Guttmann-Raviv N and Ayoub N: KDM4C (GASC1) lysine demethylase is associated with mitotic chromatin and regulates chromosome segregation during mitosis. Nucleic Acids Res 42: 6168-6182, 2014.

11. Ozaki Y, Fujiwara K, Ikeda M, Ozaki T, Terui T, Soma M, Inazawa $J$ and Nagase $\mathrm{H}$ : The oncogenic role of GASC1 in chemically induced mouse skin cancer. Mamm Genome 26: 591-597, 2015.

12. Sudo G, Kagawa T, Kokubu Y, Inazawa $J$ and Taga $T$ : Increase in GFAP-positive astrocytes in histone demethylase GASC1/KDM4C/JMJD2C hypomorphic mutant mice. Genes Cells 21: 218-225, 2016

13. Movassaghian S, Xie Y, Hildebrandt C, Rosati R, Li Y, Kim NH, Conti DS, da Rocha SR, Yang ZQ and Merkel OM: Post-transcriptional regulation of the GASC1 oncogene with active tumor-targeted siRNA-nanoparticles. Mol Pharm 13: 2605-2621, 2016

14. Jia R, Yang L, Yuan X, Kong J, Liu Y, Yin W, Gao S and Zhang Y: GASC1 promotes stemness of esophageal squamous cell carcinoma via NOTCH1 promoter demethylation. J Oncol 2019: $1621054,2019$.

15. Natsume A, Kinjo S, Yuki K, Kato T, Ohno M, Motomura K, Iwami $\mathrm{K}$ and Wakabayashi T: Glioma-initiating cells and molecular pathology: Implications for therapy. Brain Tumor Pathol 28: 1-12, 2011.

16. Roussel MF and Hatten ME: Cerebellum development and medulloblastoma. Curr Top Dev Biol 94: 235-282, 2011.

17. Yang X, Xiao Z, Du X, Huang L and Du G: Silencing of the long non-coding RNA NEAT1 suppresses glioma stem-like properties through modulation of the miR-107/CDK6 pathway. Oncol Rep 37: 555-562, 2017

18. Wesseling P and Capper D: WHO 2016 Classification of gliomas Neuropathol Appl Neurobiol 44: 139-150, 2018.

19. Weichbrod RH, Thompson GA and Norton JN (eds): Management of Animal Care and Use Programs in Research, Education, and Testing. CRC Press/Taylor \& Francis, Boca Raton, FL, 2018.

20. Chen Y: Scratch wound healing assay. Bio Protoc 2: e100, 2012.

21. Bai J, Varghese J and Jain R: Adult glioma WHO classification update, genomics, and imaging: What the radiologists need to know. Top Magn Reson Imaging 29: 71-82, 2020.

22. Delev D, Heiland DH, Franco P, Reinacher P, Mader I, Staszewski O, Lassmann S, Grau S and Schnell O: Surgical management of lower-grade glioma in the spotlight of the 2016 WHO classification system. J Neurooncol 141: 223-233, 2019.

23. Cordeiro BM, Oliveira ID, Alves MT, Saba-Silva N, Capellano AM, Cavalheiro S, Dastoli P and Toledo SR: SHH, WNT, and NOTCH pathways in medulloblastoma: When cancer stem cells maintain self-renewal and differentiation properties. Childs Nerv Syst 30: 1165-1172, 2014.
24. Xu A, Yang H, Gao K, Zhan Z, Song Z, Huang T and Song Y: Expression profiles and prognostic significance of WNT family members in glioma via bioinformatic analysis. Biosci Rep 40: 40, 2020.

25. Shahi MH, Farheen S, Mariyath MP and Castresana JS: Potential role of Shh-Gli1-BMI1 signaling pathway nexus in glioma chemoresistance. Tumour Biol 37: 15107-15114, 2016.

26. Yi L, Zhou X, Li T, Liu P, Hai L, Tong L, Ma H, Tao Z, Xie Y, Zhang $\mathrm{C}$, et al: Notch1 signaling pathway promotes invasion, self-renewal and growth of glioma initiating cells via modulating chemokine system CXCL12/CXCR4. J Exp Clin Cancer Res 38: 339, 2019.

27. Morovic W and Budinoff CR: Epigenetics: A new frontier in probiotic research. Trends Microbiol, 2020.

28. Wimalasena VK, Wang T, Sigua LH, Durbin AD and Qi J: Using chemical epigenetics to target cancer. Mol Cell 78: 1086-1095, 2020.

29. Foltz G, Yoon JG, Lee H, Ma L, Tian Q, Hood L and Madan A: Epigenetic regulation of wnt pathway antagonists in human glioblastoma multiforme. Genes Cancer 1: 81-90, 2010.

30. Nagarajan RP and Costello JF: Epigenetic mechanisms in glioblastoma multiforme. Semin Cancer Biol 19: 188-197, 2009.

31. Danussi C and Huse JT: Novel insights into the epigenetics of diffuse glioma. Mol Cell Oncol 5: e1472055, 2018.

32. Gusyatiner O and Hegi ME: Glioma epigenetics: From subclassification to novel treatment options. Semin Cancer Biol 51: 50-58, 2018.

33. Buczkowicz P and Hawkins C: Pathology, molecular genetics, and epigenetics of diffuse intrinsic pontine glioma. Front Oncol 5: 147, 2015.

34. Kallestad L, Christensen K, Woods E and Milavetz B Transcriptional repression is epigenetically marked by $\mathrm{H} 3 \mathrm{~K} 9$ methylation during SV40 replication. Clin Epigenetics 6: 21, 2014.

35. Yang ZQ, Imoto I, Fukuda Y, Pimkhaokham A, Shimada Y, Imamura M, Sugano S, Nakamura Y and Inazawa J: Identification of a novel gene, GASC1, within an amplicon at 9p23-24 frequently detected in esophageal cancer cell lines. Cancer Res 60: 4735-4739, 2000

36. Hélias C, Struski S, Gervais C, Leymarie V, Mauvieux L, Herbrecht R and Lessard M: Polycythemia vera transforming to acute myeloid leukemia and complex abnormalities including 9p homogeneously staining region with amplification of MLLT3, JMJD2C, JAK2, and SMARCA2. Cancer Genet Cytogenet 180: $51-55,2008$

37. Italiano A, Attias R, Aurias A, Pérot G, Burel-Vandenbos F, Otto J, Venissac N and Pedeutour F: Molecular cytogenetic characterization of a metastatic lung sarcomatoid carcinoma: 9p23 neocentromere and 9p23-p24 amplification including JAK2 and JMJD2C. Cancer Genet Cytogenet 167: 122-130, 2006.

38. Sun Z, Wang L, Zhou Y, Dong L, Ma W, Lv L, Zhang J and Wang X: Glioblastoma stem cell-derived exosomes enhance stemness and tumorigenicity of glioma cells by transferring Notch1 protein. Cell Mol Neurobiol 40: 767-784, 2020.

39. Zhang L, Yu H, Yuan Y, Yu JS, Lou Z, Xue Y and Liu Y: The necessity for standardization of glioma stem cell culture: A systematic review. Stem Cell Res Ther 11: 84, 2020.

40. Engh JA: Notch1 identified as a prognostic factor for glioma patients. Neurosurgery 68: N22-N23, 2011.

41. Jiang L, Wu J, Chen Q, Hu X, Li W and Hu G: Notch1 expression is upregulated in glioma and is associated with tumor progression. J Clin Neurosci 18: 387-390, 2011.

42. Li J, Cui Y, Gao G, Zhao Z, Zhang H and Wang X: Notch1 is an independent prognostic factor for patients with glioma. J Surg Oncol 103: 813-817, 2011.

43. Sun ZF, Wang L, Gu F, Fu L, Li WL and Ma YJ: Expression of Notch1, MMP-2 and MMP-9 and their significance in glioma patients. Zhonghua Zhong Liu Za Zhi 34: 26-30, 2012 (In Chinese).

44. Yu X, Zhang W, Ning Q and Luo X: MicroRNA-34a inhibits human brain glioma cell growth by down-regulation of Notch1. J Huazhong Univ Sci Technolog Med Sci 32: 370-374, 2012.

45. Ming J, Sun B, Li Z, Lin L, Meng X, Han B, Wang R, Wu P, Li J, Cai J, et al: Aspirin inhibits the SHH/GLI1 signaling pathway and sensitizes malignant glioma cells to temozolomide therapy. Aging (Albany NY) 9: 1233-1247, 2017.

46. Qiang L, Wu T, Zhang HW, Lu N, Hu R, Wang YJ, Zhao L, Chen FH, Wang XT, You QD, et al: HIF-1 $\alpha$ is critical for hypoxia-mediated maintenance of glioblastoma stem cells by activating Notch signaling pathway. Cell Death Differ 19: 284-294, 2012. 
47. Hu YY, Fu LA, Li SZ, Chen Y, Li JC, Han J, Liang L, Li L, Ji CC, Zheng MH, et al: Hif-1 $\alpha$ and Hif-2 $\alpha$ differentially regulate Notch signaling through competitive interaction with the intracellular domain of Notch receptors in glioma stem cells. Cancer Lett 349: 67-76, 2014.

48. Espinoza I and Miele L: Notch inhibitors for cancer treatment. Pharmacol Ther 139: 95-110, 2013.

49. Locatelli M and Curigliano G: Notch inhibitors and their role in the treatment of triple negative breast cancer: Promises and failures. Curr Opin Oncol 29: 411-427, 2017.

50. Komori T: Brain Tumor. Brain Nerve 72: 399-405, 2020 (In Japanese).

51. Yang ZQ, Imoto I, Pimkhaokham A, Shimada Y, Sasaki K, Oka $\mathrm{M}$ and Inazawa J: A novel amplicon at 9p23-24 in squamous cell carcinoma of the esophagus that lies proximal to GASC1 and harbors NFIB. Jpn J Cancer Res 92: 423-428, 2001.

52. Marino S: Medulloblastoma: Developmental mechanisms out of control. Trends Mol Med 11: 17-22, 2005.

53. de Bont JM, Packer RJ, Michiels EM, den Boer ML and Pieters R: Biological background of pediatric medulloblastoma and ependymoma: A review from a translational research perspective. Neuro Oncol 10: 1040-1060, 2008.

54. Mishra S: CSNK1A1 and Gli2 as novel targets identified through an integrative analysis of gene expression data, protein-protein interaction and pathways networks in glioblastoma tumors: Can these two be antagonistic proteins? Cancer Inform 13: 93-108, 2014.

55. Louis DN, Perry A, Reifenberger G, von Deimling A, Figarella-Branger D, Cavenee WK, Ohgaki H, Wiestler OD, Kleihues P and Ellison DW: The 2016 world health organization classification of tumors of the central nervous system: A summary. Acta Neuropathol 131: 803-820, 2016.
56. Vora P, Seyfrid M, Venugopal C, Qazi MA, Salim S, Isserlin R, Subapanditha M, O'Farrell E, Mahendram S, Singh M, et al: Bmi1 regulates human glioblastoma stem cells through activation of differential gene networks in $\mathrm{CD}_{133^{+}}$brain tumor initiating cells J Neurooncol 143: 417-428, 2019.

57. Chang S, Yim S and Park H: The cancer driver genes IDH1/2, JARID1C/KDM5C, and UTX/KDM6A: Crosstalk between histone demethylation and hypoxic reprogramming in cancer metabolism. Exp Mol Med 51: 1-17, 2019.

58. Sanchez-Martin M: Brain tumour stem cells: Implications for cancer therapy and regenerative medicine. Curr Stem Cell Res Ther 3: 197-207, 2008.

59. Jia R, Mi Y, Yuan X, Kong D, Li W, Li R, Wang B, Zhu Y, Kong J, Ma Z, et al: GASC1-adapted neoadjuvant chemotherapy for resectable esophageal squamous cell carcinoma: A prospective clinical biomarker trial. J Oncol 2020: 1607860, 2020.

60. Mintz A and Debinski W: Cancer genetics/epigenetics and the $X$ chromosome: Possible new links for malignant glioma pathogenesis and immune-based therapies. Crit Rev Oncog 11: 77-95, 2000.

This work is licensed under a Creative Commons Attribution-NonCommercial-NoDerivatives 4.0 International (CC BY-NC-ND 4.0) License. 